\title{
18-26 GHz Low-Noise Amplifiers Using 130- and 90-nm Bulk CMOS Technologies
}

\author{
Shih-Chieh Shin, Szu-Fan Lai, Kun-You Lin, Ming-Da Tsai, Huei Wang, Chih-Sheng Chang*, and \\ Yung-Chih Tsai* \\ Dept. of Electrical Engineering and Graduate Institute of Communication Engineering, \\ National Taiwan University, Taipei, 106, Taiwan, R.O.C. \\ *Taiwan Semiconductor Manufacturing Company, Hsinchu City, 300, Taiwan, R.O.C.
}

\begin{abstract}
Two 18-26 GHz CMOS low-noise amplifiers using 130- and 90-nm bulk CMOS technologies are described in this paper. The thin-film microstrip (TFMS) LNA using 130-nm CMOS process demonstrates a peak gain of $12.9 \mathrm{~dB}$ at $21 \mathrm{GHz}$ with 3-dB bandwidth of 18.6 to $26.3 \mathrm{GHz}$ and a noise figure (NF) of better than $5.4 \mathrm{~dB}$ between 20 and 26 GHz. The coplanar waveguide (CPW) amplitier fabricated by $90-\mathrm{nm}$ CMOS process presents a peak gain of $16.2 \mathrm{~dB}$ with a 3-dB bandwidth of 18 to $26 \mathrm{GHz}$, and a NF of better than $4 \mathrm{~dB}$ from 18 to $26 \mathrm{GHz}$.
\end{abstract}

Index Terms - CMOS, low-noise amplifier, thin-film microstrip line, coplanar waveguide.

\section{INTRODUCTION}

The rapidly growing demand for larger bandwidth motivates RF circuits to move toward higher frequencies. At frequencies above $20 \mathrm{GHz}$, GaAs-based HEMT and HBT MMICs occupied most of the applications. Recent works have illustrated the rapid development of CMOS devices to have the potential of building RF circuits at frequencies above $20 \mathrm{GHz}$. Although LNAs using SOI CMOS process demonstrated excellent performances [1], the standard bulk CMOS process is still attractive because of cost consideration. There were some reports of bulk CMOS LNAs designed for frequencies above $20 \mathrm{GHz}$, and most of them were designed using the lumped elements [2]-[3]. Several high-frequency CMOS amplifiers were designed using transmission lines to reduce the lossy substrate effect [4]-[7]. A 20- and a 40-GHz TFMS amplifiers fabricated by $90-\mathrm{nm}$ CMOS technology were reported with good agreement between the simulated and measured results [4]. A $0.18-\mu \mathrm{m}$ CMOS distributed amplifier designed using TFMS demonstrates a 4-dB gain and a $39-\mathrm{GHz}$ bandwidth [5]. A 27-GHz TFMS tuned amplifier consists of three-stage cascode cells demonstrated 17-dB gain [6]. By adopting coplanar waveguide, a $60-\mathrm{GHz}$ LNA cascaded by 3-stage cascode cells was presented [7]. It is observed that the CMOS circuits using either TFMS or CPW demonstrated good performance in high frequency range.

In this paper, we present a TFMS and a CPW LNAs fabricated using TSMC 130- and 90-nm bulk CMOS technologies, respectively. The TFMS amplifier was implemented with a very compact chip size since the thinfilm spiral inductors can be utilized in this design. The CPW LNA fabricated by $90-\mathrm{nm}$ technology demonstrates the better gain and noise performances. Table I summarizes the performances of the previously reported LNAs designed for frequencies around $20 \mathrm{GHz}$. Both of these amplifiers present the comparable gain of GaAsbased pHEMT LNA [8], with slightly higher noise performance for our 90-nm CPW CMOS design.

\section{90- AND 130-NM CMOS CHARACTERISTICS AND PROCESSES}

The TFMS and CPW amplifiers are fabricated by $130-$ $\mathrm{nm}$ one-poly-eight-metal (1P8M) and 90-nm one-polynine-metal (1P9M) processes, respectively. The 130-nm process has an $f_{\mathrm{T}}$ of $85 \mathrm{GHz}$ and an $f_{\max }$ of $90 \mathrm{GHz}$ while the $90-\mathrm{nm}$ process demonstrates an $f_{\mathrm{T}}$ of $160 \mathrm{GHz}$ and an $f_{\max }$ of $142 \mathrm{GHz}$. Both of these two processes provide the top metallization of $2-\mu \mathrm{m}$ thickness for low loss interconnection. MIM capacitors with 1 - and $1.5-\mathrm{fF} / \mu \mathrm{m}^{2}$ unit capacitance are also provided in $130-$ and $90-\mathrm{nm}$ processes, respectively.

\section{THIN-FILM MICROSTRIP LINE AND COPLANAR WAVEGUIDE IN CMOS PROCESS}

Figure I shows the structures of the TFMS and CPW. The TFMS consists of the top metal (M8) as the signal strip and bottom metal (MI) as ground plane in the 130nm CMOS process. The TFMS has the advantage of the ground plane shielding to isolate the conductive substrate. The matching elements of transmission lines can be replaced by thin-film spiral inductors or meandering lines in a very small area to reduce the circuit size. However, 
TABLE I

COMPARISON WITH PREVIOUSLY RePORTED LNAS For FreQUENCIES AROUND $20 \mathrm{GHZ.}$

\begin{tabular}{|c|c|c|c|c|c|c|c|c|}
\hline Process & $\begin{array}{l}\text { Bandwidth } \\
\text { (GHz) }\end{array}$ & $\begin{array}{l}\text { Gain } \\
\text { (dB) }\end{array}$ & $\mathrm{NF}(\mathrm{dB})$ & $\begin{array}{c}\text { Chip Size } \\
\left(\mathrm{mm}^{2}\right)\end{array}$ & $\begin{array}{l}\mathrm{P}_{\mathrm{Dc}} \\
(\mathrm{mW})\end{array}$ & $\begin{array}{c}\text { Suyply } \\
\text { Voltage (V) }\end{array}$ & Topology* & Ref. \\
\hline $0.18-\mu \mathrm{m}$ CMOS & - & 15 & $6(22 \mathrm{GHz})$ & $0.05^{*}$ & 24 & 1.5 & $\begin{array}{c}3 \text { stages, } \\
\text { CGRF+CS+CS }\end{array}$ & [2] \\
\hline $0.18-\mu \mathrm{m}$ CMOS & $22-25$ & 12.86 & $\begin{array}{c}5.6 \sim 7 \\
(23 \sim 24 \mathrm{GHz})\end{array}$ & 0.735 & 54 & 1.8 & $\begin{array}{c}3 \text { stages, } \\
\text { CS+CS+CS }\end{array}$ & [3] \\
\hline $0.18-\mu \mathrm{m}$ CMOS & $23 \sim 28$ & 8.9 & $\begin{array}{c}\overline{6.9 \sim 8} \\
(24 \sim 26 \mathrm{GHz})\end{array}$ & 0.735 & 54 & 1.8 & $\begin{array}{c}3 \text { stages, } \\
\mathrm{CS}+\mathrm{CS}+\mathrm{CS}\end{array}$ & [3] \\
\hline 90-nm CMOS & $17 \sim 28$ & 6 & $\begin{array}{c}5 \sim 7 \\
(17 \sim 20 \mathrm{GHz})\end{array}$ & 0.56 & 10 & 1.5 & $\begin{array}{l}\text { 1 stage, CS, } \\
\text { TFMS }\end{array}$ & [4] \\
\hline $\begin{array}{c}0.15-\mu \mathrm{m} \\
\text { InGaP/nGaAs } \\
\text { HEMT }\end{array}$ & $23-30$ & 14.5 & $\left(\begin{array}{c}1.6-1.9 \\
(19 \sim 33 \mathrm{GHz})\end{array}\right.$ & 0.9 & 37.5 & 2.5 & $\begin{array}{l}2 \text { stages, } \\
\mathrm{CS}+\mathrm{CS}\end{array}$ & {$[8]$} \\
\hline 130-nm CMOS & $18.6-26.3$ & 12.9 & $\begin{array}{c}4.4 \sim 5.4 \\
(20 \sim 26 \mathrm{GHz})\end{array}$ & 0.3 & 16.8 & 1.2 & $\begin{array}{c}2 \text { stages, } \\
\mathrm{CS}+\mathrm{CS} \text {, TFMS }\end{array}$ & $\begin{array}{l}\text { This } \\
\text { Work }\end{array}$ \\
\hline 90-nm CMOS & $18-26$ & 16.2 & $\begin{array}{c}2.5 \sim 4 \\
(18 \sim 26 \mathrm{GHz})\end{array}$ & 0.8 & 264 & 1.2 & $\begin{array}{c}2 \text { stages, } \\
\mathrm{CS}+\mathrm{CS}, \mathrm{CPW}\end{array}$ & $\begin{array}{l}\text { This } \\
\text { Work }\end{array}$ \\
\hline
\end{tabular}

the characteristic impedance of the TFMS is dominated by the signal strip width, high-impedance lines are difficult to be implemented due to the thin $\mathrm{SiO}_{2}$ layer of $5.5 \mu \mathrm{m}$.

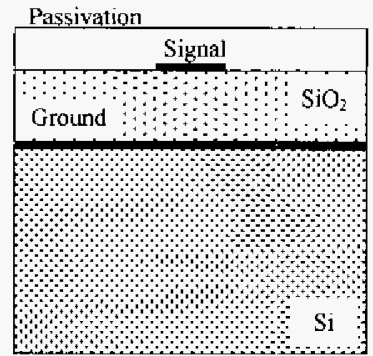

(a)

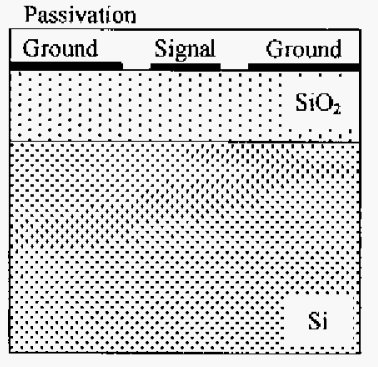

(b)
Fig. 1. The structures of the (a) TFMS, and (b) CPW on bulk CMOS process.

CPW is constructed by one signal strip and two ground metals on the same plane as shown in Fig. 1(b), and the signal and ground metals are implemented by the top metal. The characteristic impedance of the CPW is defined by the signal metal width and the gap size between signal and ground metal, thus it is more flexible to realize different impedances of CPWs. To suppress the unwanted odd-mode signal, the two ground planes of CPW should be forced to be equal potential. It is easy to implement by using the second metal to connect the two ground planes in CMOS process. The conductive substrate effect is reduced by using CPW, however it is not fully removed. Thus the substrate effect of CPW still needs to be considered. The TFMS can be meandered in very compact size, but not for CPW because CPW needs the well-defined ground planes.

\section{CMOS LNA USING TFMS}

This amplifier fabricated by $130-\mathrm{nm}$ 1P8M CMOS process is a two-stage single-ended design. The transistors in each stage are 18 fingers with a total gate periphery of $36 \mu \mathrm{m}$. Figure 2 shows the schematic, and the corresponding chip photo is shown in Fig. 3. The matching networks consist of series and shunt inductors to transform the impedance to $50 \Omega$. In order to minimize the circuit size, the thin-film spiral inductors are used as the matching elements. The source inductors implemented by the transmission lines are utilized in both stages for stability concern. All of the passive elements include thin-film spiral inductors, capacitors and transmission lines are simulated using the EM simulator Sonnet. The chip size is $0.77 \times 0.4 \mathrm{~mm}^{2}$.

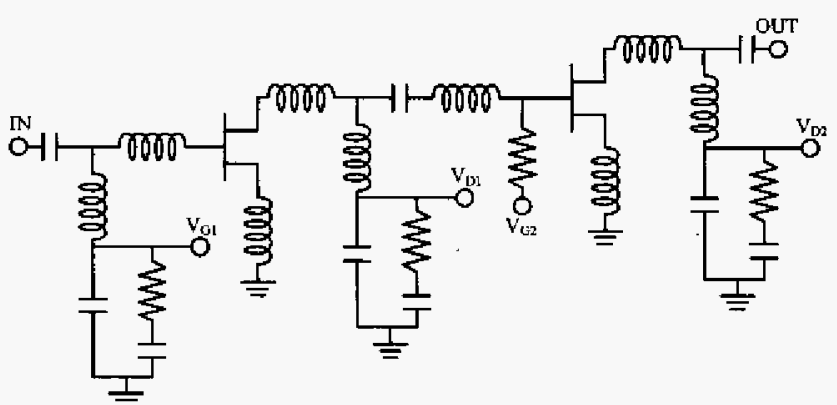

Fig. 2. Schematic of the TFMS LNA. 


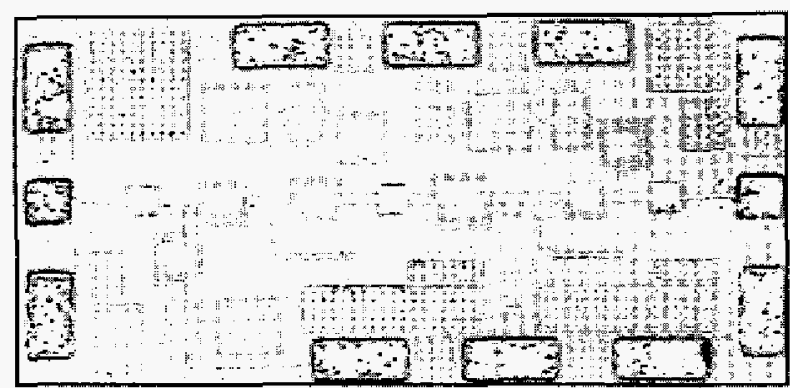

Fig. 3. Chip photo of the TFMS LNA with a chip size of $0.77 \mathrm{x}$ $0.4 \mathrm{~mm}^{2}$.

The measured small-signal gain and return losses are shown in Fig. 4 under $1.2 \mathrm{~V}$ with a total power consumption of $16.8 \mathrm{~mW}$. The measured peak gain is $12.9 \mathrm{~dB}$ at $21 \mathrm{GHz}$ with the gain higher than $10 \mathrm{~dB}$ from 18.6 to $26.3 \mathrm{GHz}$. The input return loss is better than 10 $\mathrm{dB}$ between 18.6 and $23.8 \mathrm{GHz}$, and the output return loss is better than $10 \mathrm{~dB}$ above $19.6 \mathrm{GHz}$. Figure 5 shows the measured noise figure, and this amplifier has a noise figure of better than $5.4 \mathrm{~dB}$ from 20 to $26 \mathrm{GHz}$.

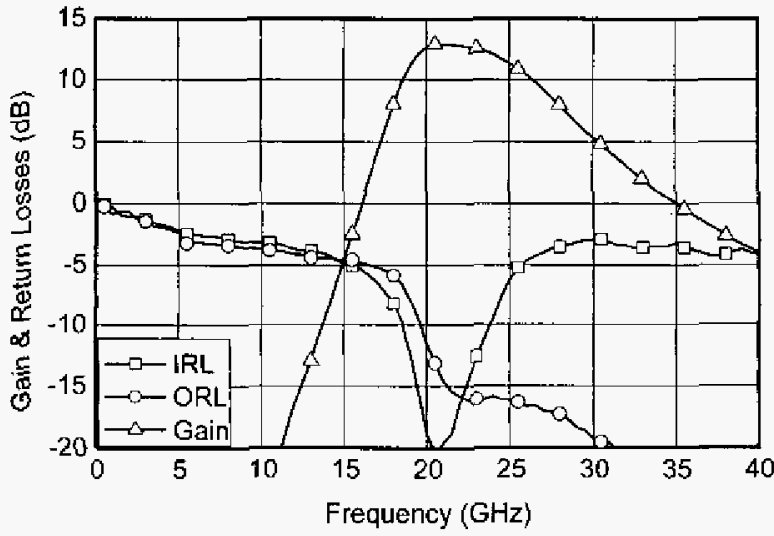

Fig. 4. Measured small-signal gain and retum losses of the TFMS LNA.

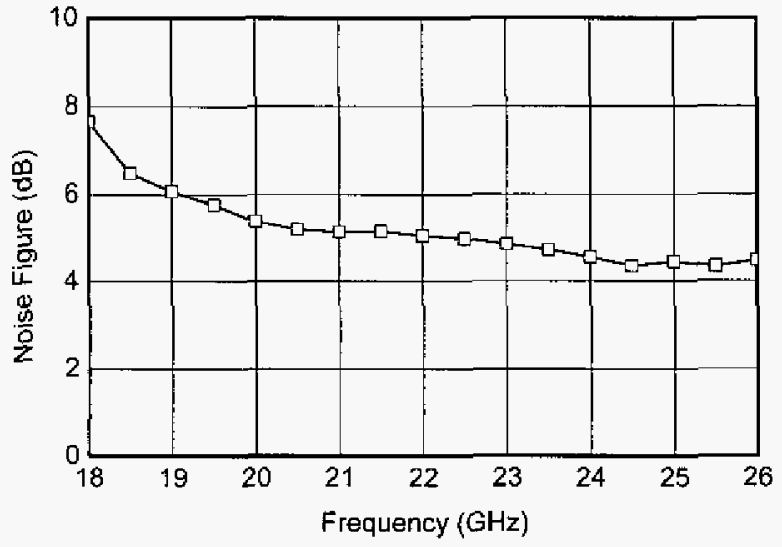

Fig. 5. Measured noise figure of the TFMS LNA.

\section{CMOS LNA USING CPW}

This amplifier which is fabricated in the 90-nm 1P9M CMOS process employs a two-stage cascaded commonsource structure. Both transistors in this circuit are 16 fingers with a total gate width of $64 \mu \mathrm{m}$. Figure 6 shows the schematic, and the corresponding chip photo is shown in Fig. 7. The input and output are matched to $50 \Omega$ by series transmission lines as well as short stubs. The technique of source degeneration is utilized in both stages for stability concern. The second stage employs a parallel resistive feedback, which leads to a broadband response. The matching elements of CPWs are meandered to achieve a smaller chip size of $0.98 \times 0.82 \mathrm{~mm}^{2}$.

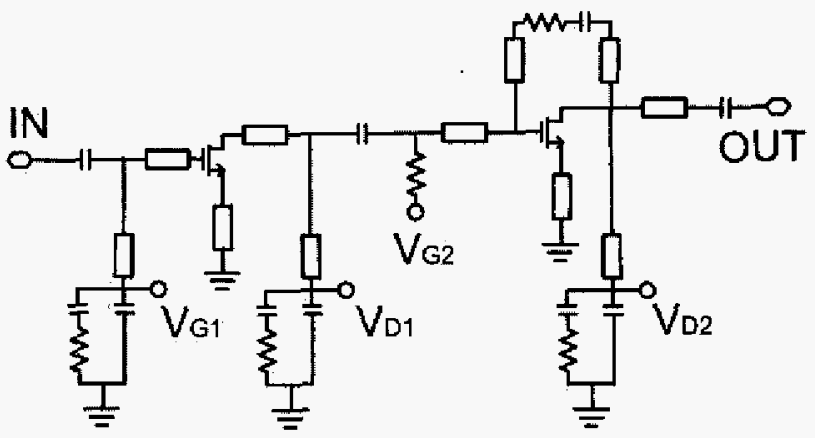

Fig. 6. Schematic of the CPW LNA.

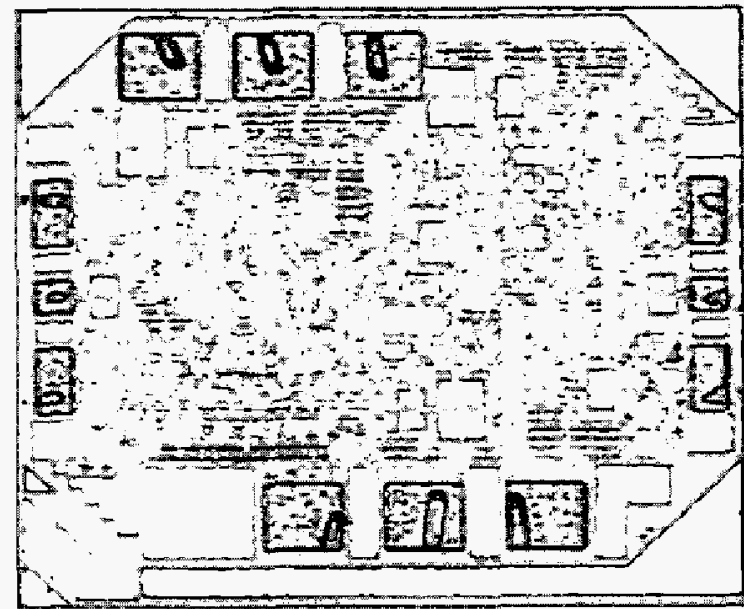

Fig. 7. Chip photo of the CPW LNA with a chip size of $0.98 \mathrm{x}$ $0.82 \mathrm{~mm}^{2}$.

The measured small-signal gain and retum losses are shown in Fig. 8 under $1.2 \mathrm{~V}$ with a total power consumption of $26.4 \mathrm{~mW}$. The measured peak gain is $16.2 \mathrm{~dB}$ at $20.5 \mathrm{GHz}$ with the $3-\mathrm{dB}$ bandwidth of $8 \mathrm{GHz}$ from 18 to $26 \mathrm{GHz}$. Figure 9 shows the measured noise figure, and this amplifier has a noise figure of better than 4 $\mathrm{dB}$ in the entire 3 - $\mathrm{dB}$ bandwidth. At $22.5 \mathrm{GHz}$, the noise figure achieves a minimum of $2.5 \mathrm{~dB}$ which is the lowest 
NF among the reported MMIC LNAs using bulk CMOS processes in this frequency.

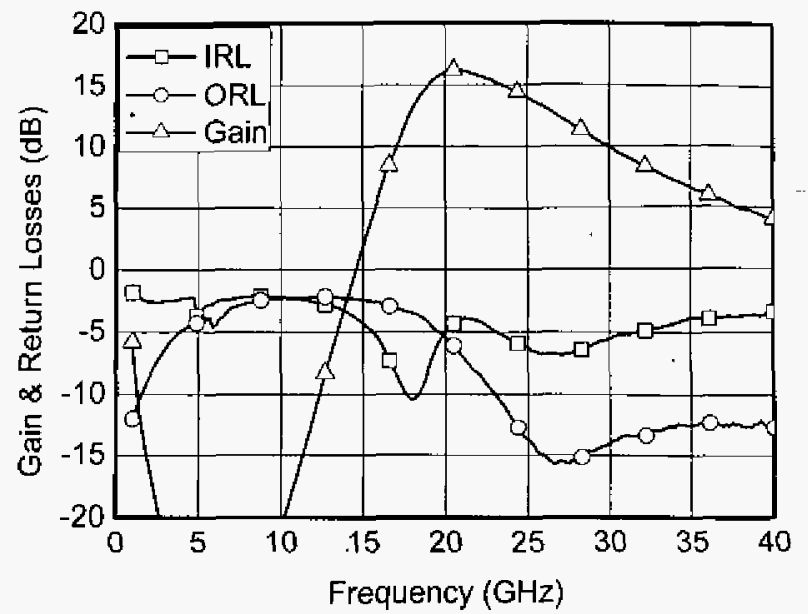

Fig. 8. Measured small-signal gain and teturn losses of the CPW LNA.

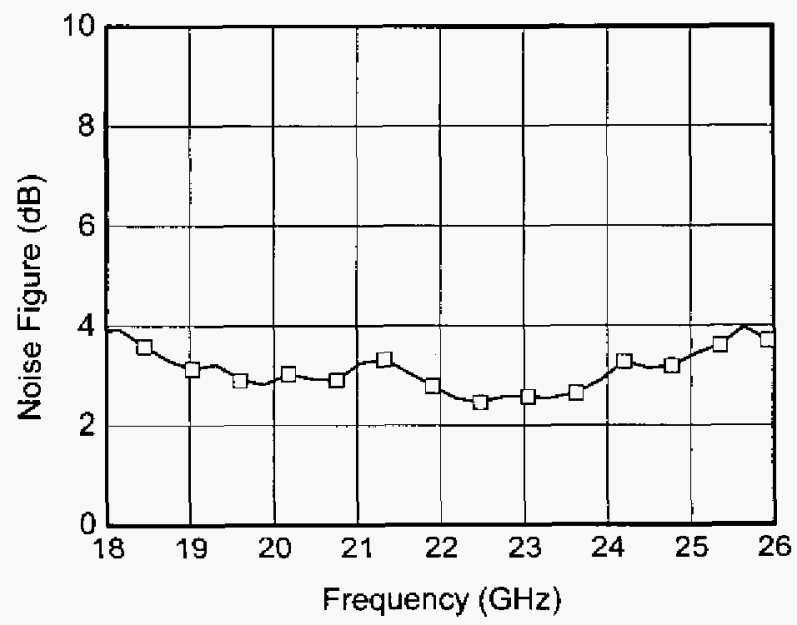

Fig. 9. Measured noise figure of the CPW LNA.

\section{CONCLUSION}

The 130- and 90-nm CMOS LNAs were developed using TFMS and CPW, respectively. These two amplifiers demonstrate wideband characteristics and good gain and noise performance. Both of the TFMS and CPW can reduce the effect of lossy substrate, thus they are the better alternatives than the lumped elements in millimeterwave CMOS circuit designs.

\section{ACKNOWLEDGEMENT}

This work is supported in part by NTU-TSMC JointDevelopment Project and National Science Council of Taiwan R.O.C. (Projects NSC 93-2219-E-002-016, NSC 93-2219-E-002-024, NSC 93-2213-E-002-033, and NSC 93-2752-E-002-002-PAE).

\section{REFERENCES}

[1] Frank Ellinger, "26-42 GHz SOI CMOS low noise amplifier," IEEE J. Solid-State Circuits, vol. 39, no. 3, pp. 522-528, March 2004

[2] Xian Guan, and Ali Hajimiri, "A 24-GHz CMOS front end," IEEE J. Solid-State Circuits, vol. 39 , no. 2, pp. 368373, Feb. 2004.

[3] K.-W. Yu, Y.-L. Lu, D.-C. Chang, Victor Liang, and M. Frank Chang, "K-Band low-noise amplifiers using $0.18 \mu \mathrm{m}$ CMOS technology," IEEE Microwave And Wireless Components Lett, vol. 14, no. 3, pp. 106-108, March 2004.

[4] A. Masud, H. Zirath, M. Ferndahl, and H.-O. Vickes, "90 nm CMOS MMIC amplifier," 2004 RFIC symp. Dig., 2004, pp. 971-974,

[5] H. Shigematsu, M. Sato, T. Hirose, F. Brewer, and M. Rodwell, "40Gb/s CMOS distributed amplifier for fiberoptic communication systems," ISSCC Dig. Tech. Papers, pp. 476-477, Feb. 2004.

[6] H. Shigematsu, T. Hirose, F. Brewer, and M. Rodwell, "CMOS circuit design for millimeter-wave applications," 2004 RFIC symp. Dig., 2004, pp. 123-126.

[7] C. H. Doan, S. Emami, A. M. Niknejad, and R. W. Brodersen, "Design of CMOS for $60 \mathrm{GHz}$ applications," ISSCC Dig. Tech. Papers, pp. 440-441, Feb. 2004.

[8] Y. Mimino, M. Hirata, K. Nakamura, K. Sakamoto, Y. Aoki, and S. Kuroda, "High gain-density K-band P-HEMT LNA MMIC for LMDS and satellite communication," in Proc. IEEE MTT-S Int. Microwave Symp., vol. 1, June 2000, pp. 17-20. 